\title{
Desempenho de sementes nuas e revestidas de azevém-anual em condições de estresse salino ${ }^{1}$
}

\author{
Amanda Votto Klafke², Rodrigo Ramos Lopes ${ }^{3}$, Lúcia Brandão Franke ${ }^{4}$
}

\footnotetext{
1 Pesquisa financiada com apoio da Coordenadoria de Aperfeiçoamento de Pessoal de Nível Superior (CAPES).

2 Programa de Pós-Graduação em Zootecnia, Faculdade de Agronomia, Universidade Federal do Rio Grande Sul. Bolsista CAPES.

3 Programa de Pós-Graduação em Zootecnia, Faculdade de Agronomia, Universidade Federal do Rio Grande Sul.

${ }^{4}$ Departamento de Plantas Forrageiras e Agrometeorologia da Faculdade de Agronomia/UFRGS, Caixa Postal 15100, 91501-970, Porto Alegre, RS.
}

RESUMO - Com o objetivo de avaliar o efeito do revestimento de sementes decorrente do aumento da concentração salina, sementes de azevém (Lolium multiflorum Lam.), cultivar “comum”, nuas e revestidas, foram expostas a seis concentrações de cloreto de sódio ( $\mathrm{NaCl}$ ): 48, 66, 97, 129 e 145 mM. O material-base empregado no revestimento foi farelo de madeira. Avaliaram-se a emergência de plântulas normais, anormais, sementes dormentes e mortas, o índice de velocidade de emergência, o comprimento da parte aérea e da raiz e o peso fresco da parte aérea das plântulas. A análise dos resultados permitiu concluir que a emergência de sementes nuas e revestidas de azevém-anual decresce com o aumento da salinidade do meio, afetando negativamente o desenvolvimento de plântulas normais. O aumento dos níveis de $\mathrm{NaCl}$ faz as sementes entrar em dormência. O revestimento usado nas sementes não é capaz de protegê-las da ação prejudicial da salinidade a partir da concentração de $64 \mathrm{mM}$ de $\mathrm{NaCl}$.

Palavras-chave: cloreto de sódio, germinação, Lolium multiflorum, vigor

\section{Performance of loose and coated ryegrass seeds under saline stress conditions}

\begin{abstract}
With the objective of evaluating the influence of seed coating on seed germination and seedling development under increased saline concentrations, naked and loose seeds of ryegrass (Lolium multiflorum Lam.), "common" cultivar, were exposed to six $\mathrm{NaCl}$ concentrations (0, 48, 66, 97, 129 and $145 \mathrm{mM}$ ). The basic material for coating was wood bran. Emergence, abnormal seedlings, dormant seeds and percentages of dead seeds, as well as speed emergence index, length of the aerial part and the root and fresh weight of the aerial part were evaluated. Results showed that emergence of both loose and coated annual ryegrass seeds decreases with increase in substrate salinity, negatively affecting seedling development. Increased $\mathrm{NaCl}$ concentration leads to seed dormancy. Seed coating is unable to protect seeds from the deleterious effects of salinity from the $64 \mathrm{mM} \mathrm{NaCl}$ concentration.
\end{abstract}

Key Words: germination, Lolium multiflorum, sodium chloride, vigor

\section{Introdução}

O estado do Rio Grande do Sul é grande produtor de arroz irrigado no Brasil, com cerca de 650.000 ha de áreas cultivadas e que permanecem anualmente em pousio (Quadros \& Bandinelli, 2005). Para utilização mais rentável e intensiva das áreas de várzea durante o inverno, tem-se como alternativa o uso de pastagens cultivadas, que é uma opção para a escassez de pasto durante o período.

O azevém-anual (Lolium multiflorum Lam.) é a forrageira de mais ampla utilização no Rio Grande do Sul (Terra-Lopes et al., 2009), assim como na maior parte das regiões temperadas e subtropicais do mundo, destacando-se entre as espécies mais difundidas mundialmente (Bresolin, 2007). Apresenta resistência ao frio, boa qualidade nutricional e potencial de produção de matéria seca (Pereira et al., 2008). Possui considerável capacidade de rebrota, boa ressemeadura natural, boa aceitação pelos animais e potencial de produção de 2 a 6 t MS/ha (Santos et al., 2002). Essas características justificam sua preferência pelos produtores na formação de pastagens de forrageiras de clima temperado, tanto em cultivo puro como em consórcio.

No entanto, cerca de 200.000 ha de várzeas utilizadas na atividade agrícola podem ser afetados por salinidade dos solos no estado (Machado \& Terres, 1995), devido à presença de cloreto de sódio ( $\mathrm{NaCl}$ ) (Asch et al., 2000). 
A inibição do processo germinativo (etapa fundamental ao estabelecimento da pastagem) ocasionada pela salinidade deve-se tanto ao efeito osmótico como ao efeito tóxico e promove distúrbios fisiológicos à semente, podendo causar sua morte (Tobe et al., 2000). O excesso de $\mathrm{Na}^{+}$e de $\mathrm{Cl}^{-}$no protoplama ocasiona distúrbios específicos sobre as enzimas e membranas celulares (Larcher, 2000).

Com a necessidade de aperfeiçoar a germinação em ambientes adversos, a técnica do revestimento é uma estratégia muito difundida atualmente em sementes pequenas. Este é um mecanismo de aplicação de materiais, inertes ou não, sobre as sementes com o objetivo de se obter um conjunto de características favoráveis ao seu redor e que, em condições naturais, não seriam alcançadas. De qualquer forma, é necessário atentar-se que o principal objetivo do revestimento é melhorar o comportamento da semente, tanto fisiológico como do aspecto econômico (Sampaio \& Sampaio, 1994).

Objetivou-se avaliar o desempenho de sementes nuas e revestidas de azevém-anual (Lolium multiflorum Lam.) sob níveis crescentes de concentração salina.

\section{Material e Métodos}

O experimento foi conduzido no Laboratório de Análise de Sementes, na Fundação Estadual de Pesquisa Agropecuária (FEPAGRO), Porto Alegre, Rio Grande do Sul. Foram utilizadas sementes de azevém (Lolium multiflorum L.), variedade "comum", provenientes do município de Júlio de Castilhos, Rio Grande do Sul, colhidas em 2006. O lote de sementes apresentou 97\% de pureza e $15 \%$ de umidade.

Para obtenção de duas amostras do lote de sementes, as mesmas foram homogeneizadas e divididas em divisor de solo, originando assim duas porções iguais, uma de sementes nuas e outra de sementes revestidas.

O processo de revestimento das sementes foi feito pela empresa Rigrantec ${ }^{\circledR}$ empregando-se como material-base farelo de madeira. Após o processamento, o formato da semente foi mantido, no entanto, seu tamanho e peso aumentaram.

Foram testadas seis concentrações de $\mathrm{NaCl}$ 99\% (0, 48, 64, 97, 129, e 145 mM). O potencial osmótico das soluções salinas foi medido diretamente por um Vapor Pressure Osmometer, modelo 5520 da marca Wescor (Tabela 1).

As unidades experimentais foram constituídas de copos plásticos de $700 \mathrm{~mL}$ de capacidade, utilizando-se um substrato composto por areia e vermiculita, na proporção de 2:1. Durante a condução do ensaio, manteve-se o teor de água do substrato em $70 \%$ da capacidade de retenção
Tabela 1 - Relação entre a concentração de $\mathrm{NaCl}$ e o potencial osmótico da solução salina

\begin{tabular}{|c|c|}
\hline Concentração de $\mathrm{NaCl}(\mathrm{mM})$ & Potencial osmótico (MPa) \\
\hline 0 & 0,0 \\
\hline 48 & $-0,8$ \\
\hline 64 & $-0,9$ \\
\hline 97 & $-1,4$ \\
\hline 129 & $-2,1$ \\
\hline 145 & $-2,2$ \\
\hline
\end{tabular}

determinada, adicionando-se $200 \mathrm{~mL}$ de água a $500 \mathrm{~g}$ do substrato colocado em funil, calculando-se a retenção por diferença após drenagem do excesso deágua (Fretz et al., 1979).

A superação da dormência foi realizada pela metodologia de pré-esfriamento na temperatura de $8 \pm 1^{\circ} \mathrm{C}$ por oito dias (Eichelberger et al., 2001). Logo após, as sementes foram encaminhadas para germinação em condições ambientais. Utilizaram-se quatro sementes por recipiente, semeadas a $2 \mathrm{~cm}$ de profundidade, com cinco repetições por concentração de $\mathrm{NaCl}$ testada $(0,48,64,97,129$, e $145 \mathrm{mM})$.

O suprimento de solução salina foi feito por meio de um borrifador, sempre que necessário. As sementes germinadas foram observadas diariamente por um período de 14 dias, sendo consideradas germinadas desde a aparição das primeiras estruturas radiculares na superfície do substrato.

Foram avaliadas as seguintes variáveis: porcentagem de plântulas normais, plântulas anormais, sementes dormentes e sementes mortas, além de índice de velocidade de emergência, comprimento da parte aérea e das raízes e peso fresco da parte aérea da plântula.

As porcentagens de plântulas normais e anormais foram calculadas após 14 dias, pela contagem direta das cinco repetições por concentração salina. Os resultados foram expressos em porcentagem (\%).

O índice de velocidade de emergência (IVE) foi obtido durante 14 dias e as avaliações realizadas diariamente a partir do aparecimento das primeiras estruturas radiculares na superfície do substrato. Após o período de 14 dias, as sementes não germinadas foram avaliadas pelo teste de tetrazólio. Na primeira etapa, as sementes foram submetidas a um pré-condicionamento durante 14 a 18 horas em água destilada para facilitar o corte longitudinal da cariopse. A seguir, as cariopses foram cuidadosamente cortadas e os embriões colocados em copos plásticos, sendo totalmente submersos em solução de tetrazólio a $0,5 \%$ e mantidos no escuro à temperatura de $25^{\circ} \mathrm{C}$ por 4 a 5 horas. A avaliação da viabilidade das sementes foi baseada no padrão colorimétrico utilizado para sementes de pensacola (Delouche, 1976).

O comprimento da parte aérea e das raízes das plântulas (cm) foi obtido por medição direta com o auxílio de um 
paquímetro e o peso fresco da parte aérea das plântulas (g), pela pesagem em balança eletrônica (precisão de 0,0001 g).

O delineamento experimental foi completamente casualizado, em esquema fatorial [2 amostras (sementes nuas e revestidas) $\times 6$ concentrações de $\mathrm{NaCl}$ )] com cinco repetições por tratamento. Os dados foram submetidos à análise de variância pelo procedimento PROC GLM do programa SAS ${ }^{\circledR}$ (Statistical Analysis System, versão 9.1.3) e, em caso de diferença significativa, as médias foram comparadas pelo teste Duncan (5\%).

O efeito das concentrações de $\mathrm{NaCl}$ nas porcentagens de plântulas normais, de plântulas anormais, de sementes dormentes eíndice de velocidade de emergência foi analisado por análises de variância e de regressão e os graus de liberdade da variável avaliada foram desdobrados nos efeitos linear, quadrático e cúbico pelo procedimento PROC REG (Statistical Analysis System, versão 9.1.3.), para escolha do modelo de regressão. Foi considerado o maior valor do coeficiente de determinação $\left(\mathrm{R}^{2}\right)$ a $\mathrm{P} \leq 0,05$ de acordo com o teste $\mathrm{F}$, respeitando-se a resposta biológica da espécie.

O modelo matemático geral referente à análise das variáveis estudadas foi representado por:

$\mathrm{Y}_{\mathrm{ij}}=\mu+\mathrm{T}_{\mathrm{i}}+\mathrm{CL}_{\mathrm{j}}+(\mathrm{T} \times \mathrm{C})_{\mathrm{ij}}+\varepsilon_{\mathrm{ij}}$

em que $\mathrm{Y}_{\mathrm{ij}}=$ variáveis dependentes (porcentagens de emergência, plântulas anormais, de sementes dormentes, de sementes mortas, além de índice de velocidade de emergência, comprimento da parte aérea e das raízes e peso fresco da parte aérea da plântula); $\mu$ = média de todas as observações; $\mathrm{T}_{\mathrm{i}}=$ efeito do revestimento $\mathrm{i}, \mathrm{i}$ = semente nua, semente revestida; $\mathrm{C}_{\mathrm{j}}=$ efeito da concentração de $\mathrm{NaCl} \mathrm{j}$, $\mathrm{j}=0,48,64,97,129$, e $145 \mathrm{mM} ;(\mathrm{T} \times \mathrm{C})_{\mathrm{ij}}=$ interação revestimento i $\times$ concentração de $\mathrm{NaClj} ; \varepsilon_{\mathrm{ij}}=$ erro aleatório associado a cada observação ij. Assume-se que $\varepsilon_{\mathrm{ij}} \sim$ NID $\left(0, \sigma^{2}\right)$.

\section{Resultados e Discussão}

A interação entre sementes nuas/revestidas e concentração de $\mathrm{NaCl}$ não teve efeito significativo $(\mathrm{P}>0,05)$ sobre nenhuma das variáveis estudadas. Os efeitos encontrados neste estudo evidenciam que o aumento da concentração de $\mathrm{NaCl}$, expresso pela redução do potencial osmótico, prejudica a germinação e o crescimento inicial de azevém-anual.

Por meio da análise de variância da porcentagem de plântulas normais, constatou-se que houve significância apenas para o efeito isolado da concentração de $\mathrm{NaCl}$. $\mathrm{Na}$ avaliação do comportamento das sementes, observou-se que o decréscimo de plântulas normais foi linear de acordo com o aumento das concentrações de $\mathrm{NaCl}$ (Figura 1).
Diversos trabalhos têm sido desenvolvidos com outras espécies de sementes pequenas e os resultados encontrados sugerem que, à medida que ocorre redução no potencial osmótico da solução, tornando-o mais negativo pelo aumento da concentração salina, reduz a porcentagem de germinação das sementes, como em cenoura (Lopes \& Dias, 2004) e couve-chinesa (Lopes \& Macedo, 2008). O aumento da concentração salina reduz o potencial osmótico da solução, diminuindo o potencial hídrico associado aos efeitos tóxicos dos sais interferem inicialmente no processo de absorção de água pelas sementes, influenciando na germinação (Tobe et al., 2000).

$\mathrm{O}$ aumento na concentração salina provocou maior incidência de plântulas anormais até $64 \mathrm{mM}$ de $\mathrm{NaCl}$, observando-se a diminuição da incidência de anormalidades nas concentrações mais altas (97, 129 e 145 mM) (Figura 2). Para as sementes germinam nessas condições de salinidade, os efeitos negativos são acumulativos desde a sinalização

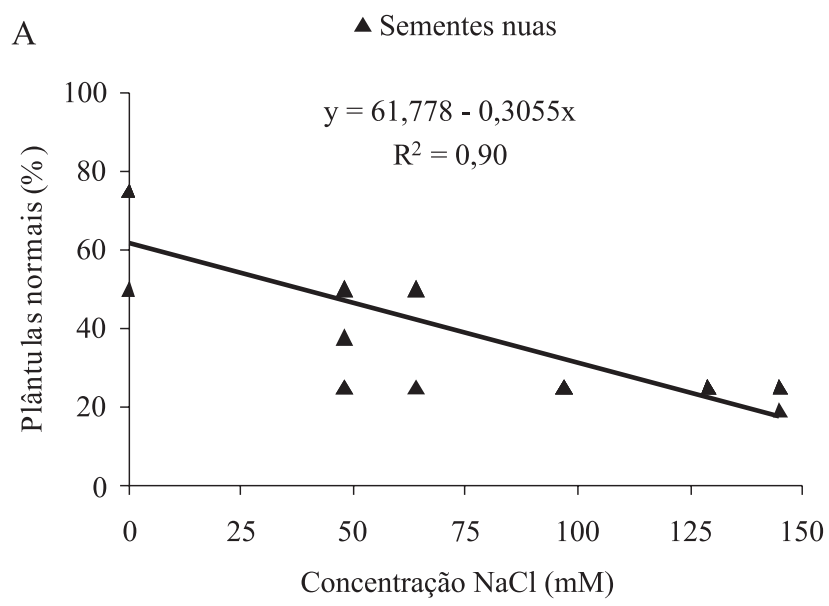

B

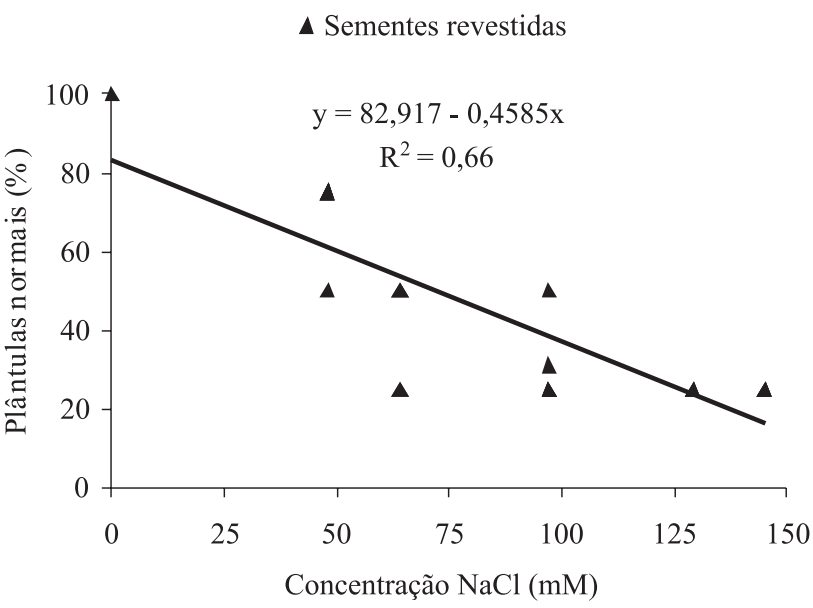

Figura 1 - Porcentagem de plântulas normais de sementes nuas (A) e revestidas (B) de azevém-anual (Lolium multiflorum L.) em diversas concentrações de $\mathrm{NaCl}$ (mM). 
A

$\Delta$ Sementes nuas

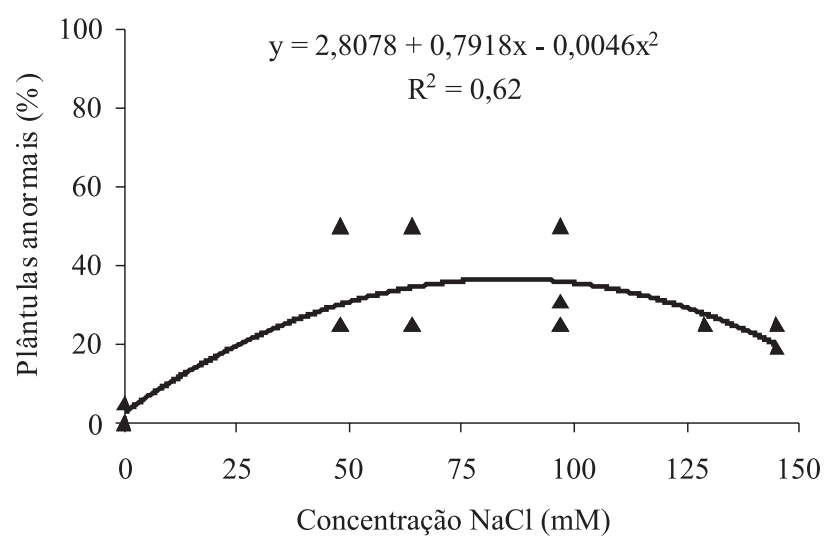

B

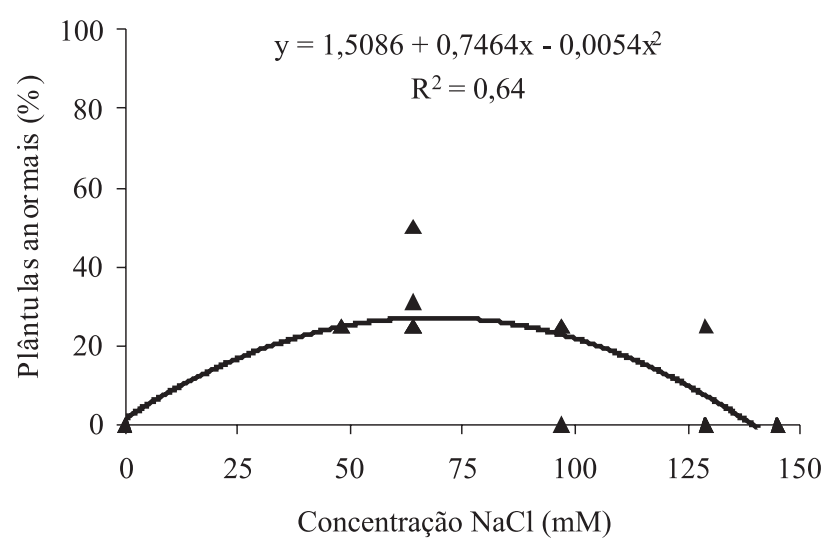

Figura 2 - Porcentagem de plântulas anormais de sementes nuas (A) e revestidas (B) de azevém-anual (Lolium multiflorum L.) em diversas concentrações de $\mathrm{NaCl}$ (mM).

e ativação do mecanismo de germinação, aumentando a probabilidade de degenerações no desenvolvimento da plântula.

O efeito tóxico dos sais sobre os tecidos vivos da semente em processo de germinação é mais intenso nos tecidos do eixo embrionário, os quais possuem células bastante sensíveis à salinidade (Dantas et al., 2003). A restrita absorção de água dada pelo gradiente osmótico afeta diretamente o desenvolvimento do embrião, o qual depende de processos de divisão e expansão (turgescência) celulares.

O menor número de plântulas anormais emergidas a partir de $64 \mathrm{mM}$ de $\mathrm{NaCl}$ evidencia uma estratégia da semente na presença de altas concentrações de sal, a dormência. Este estado "dormente" caracteriza-se pela incapacidade de germinação das sementes mesmo quando expostas a condições ambientais favoráveis, ocorrendo de forma primária, quando já está presente nas sementes colhidas e de forma secundária, quando é causada por alterações fisiológicas provocadas por exposição a condições desfavoráveis à germinação após a colheita (Floriano, 2004).

Houve aumento significativo na porcentagem de sementes dormentes à medida que aumentou a concentração de $\mathrm{NaCl}$. Os maiores percentuais foram observados a partir de $64 \mathrm{mM}$ (Figura 3).

Essa resposta coincide com relatos de Cavalcante \& Perez (1995) de que, geralmente, sementes que permanecem em meio germinativo com reduzido potencial hídrico apresentam-se envoltas por uma substância de aspecto gelatinoso liberada por elas, para reduzir a área de contato com a solução. Desse modo, com o aumento da concentração salina, as sementes encontram condição de maior estresse, tendendo a entrar em estado de dormência, de modo a preservar sua espécie.

O percentual de sementes mortas não foi significativo na interação dos efeitos revestimento × concentração de $\mathrm{NaCl}$, tampouco nos efeitos isolados desses fatores (Tabela 2).

A

$\Delta$ Sementes nuas

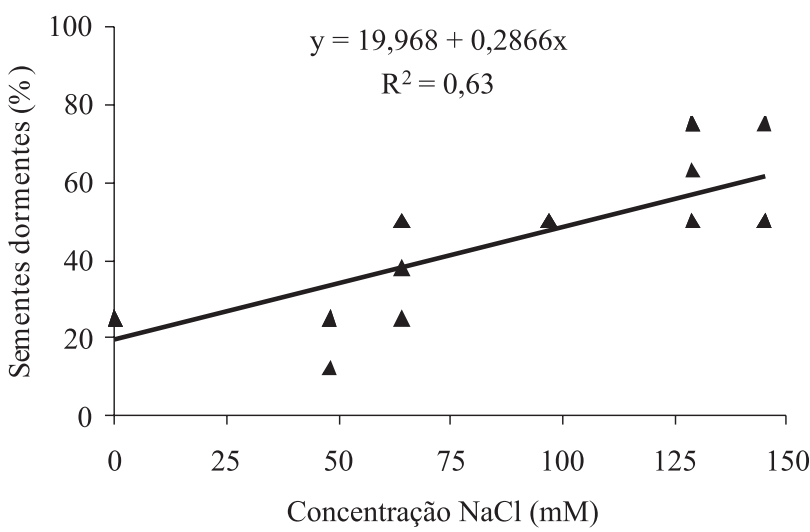

B

\ Sementes revestidas

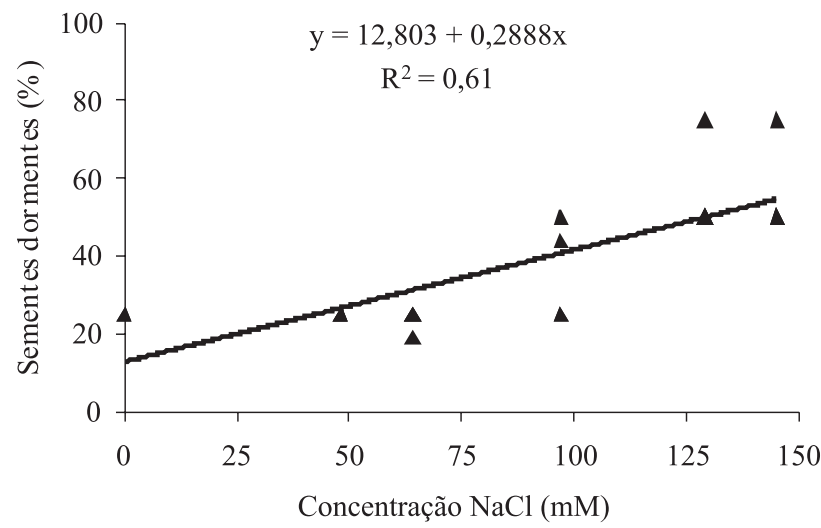

Figura 3 - Porcentagem de dormência de sementes nuas (A) e revestidas (B) de azevém-anual (Lolium multiflorum L.) em diversas concentrações de $\mathrm{NaCl}(\mathrm{mM})$. 
Tabela 2 - Porcentagem de sementes mortas entre sementes nuas e revestidas de azevém-anual (Lolium multiflorum L.) em diversas concentrações de $\mathrm{NaCl}(\mathrm{mM})$

\begin{tabular}{cccc}
\hline Concentração $\mathrm{NaCl}(\mathrm{mM})$ & \multicolumn{2}{c}{ Sementes mortas $(\%)$} & \multirow{2}{*}{ Médias } \\
\cline { 2 - 3 } & Sementes nuas & Sementes revestidas & $10 \mathrm{a}$ \\
48 & 10 & 10 & $10 \mathrm{a}$ \\
64 & 20 & 15 & $12 \mathrm{a}$ \\
97 & 5 & 19 & $18 \mathrm{a}$ \\
129 & 5 & 30 & $16 \mathrm{a}$ \\
145 & 6 & 19 & $17 \mathrm{~A}$ \\
Médias & 13 & $\mathrm{a}$ & \\
\hline
\end{tabular}

Médias seguidas de mesma letra minúscula nas colunas e maiúsculas nas linhas não diferem $(\mathrm{P}>0,05)$ pelo teste Duncan.

O aumento na concentração salina reduziu a velocidade de emergência (IVE), ou seja, quanto mais negativo o potencial osmótico, mais lento foi o processo germinativo (Figura 4).

Os efeitos tornaram-se marcantes a partir da concentração de $48 \mathrm{mM}$ de $\mathrm{NaCl}$. Essa diminuição da velocidade de germinação com outras espécies de gramíneas também foi observada por Damiani et al. (2003) em sementes de

A

$\Delta$ Sementes nuas

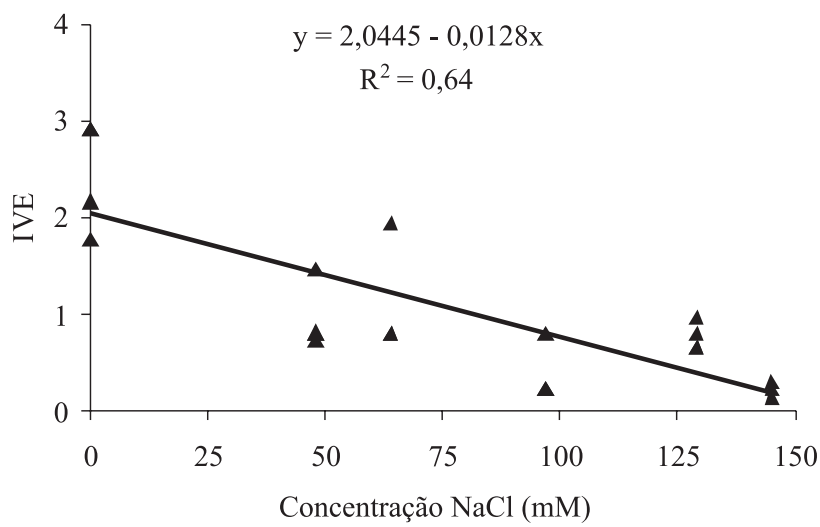

B
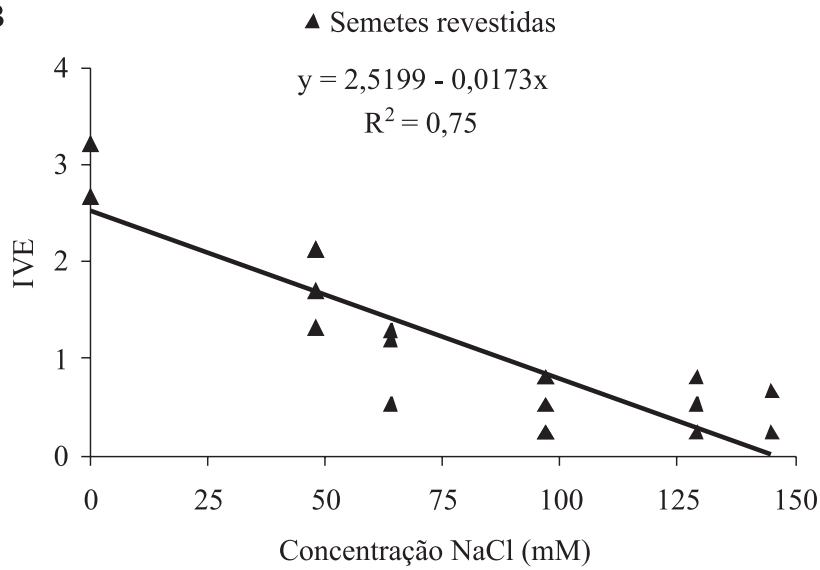

Figura 4 - Índice de velocidade de emergência (IVE) de sementes nuas (A) e revestidas (B) de azevém-anual (Lolium multiflorum L.) em diversas concentrações de $\mathrm{NaCl}$ (mM). trigo (Triticum aestivum L.) sob estresse salino e por Silva et al. (2007) em sementes de cevada.

A concentração elevada de sais aumenta o potencial osmótico no substrato, que reduz a disponibilidade de água para as plantas, afetando diretamente a velocidade de emergência (Verslues et al., 2006). Segundo Cavalcante \& Perez (1995), a diminuição do processo de absorção de água e a entrada de íons em quantidade suficiente para provocar toxicidade às sementes, especialmente o $\mathrm{NaCl}$, são apontadas como as principais causas da redução da velocidade dos processos fisiológicos e bioquímicos e, com isso, as plântulas resultantes desse meio, com menor grau de umidade, apresentam menor desenvolvimento.

Não houve efeito significativo da interação dos fatores revestimento $\times$ concentração de $\mathrm{NaCl}$ sobre o comprimento da parte aérea (CPA), somente para o efeito isolado de concentração de $\mathrm{NaCl}$ (Tabela 3).

Houve pouca variação entre os comprimentos das partes aéreas das plântulas com o aumento das concentrações de $\mathrm{NaCl}$, praticamente não havendo diferenças do tratamento controle $(0 \mathrm{mM})$. Essas informações não são compatíveis com as observações de Queiroga et al. (2006), em sementes de híbridos de melão e Torres (2007) com sementes de melancia sob vários níveis de salinidade e potenciais osmóticos, respectivamente. De acordo com Wang \& Nil (2000), durante o efeito da salinidade, determinados processos são danificados, como a síntese de proteínas, o metabolismo de lipídios e a fotossíntese. Uma das respostas iniciais é a redução da expansão da superfície foliar, acompanhada de intensificação do estresse.

O comprimento de raiz, segundo a análise de variância, apresentou significância apenas para o efeito isolado de concentração de $\mathrm{NaCl}$ (Tabela 4).

Observou-se um comportamento variável quanto ao comprimento, que aparentemente cresceu com o aumento das contrações de $\mathrm{NaCl}$ (com exceção da concentração $129 \mathrm{mM}$ ). Esse fato pode estar relacionado à diminuição do potencial hídrico, ocorrendo aumento no comprimento da 
raiz no sentido de aumentar a área superficial específica da mesma para atingir maior área de contato com a solução do substrato de germinação. Segundo Kramer \& Boyer (1995), em condições estressantes, ocorre inibição do crescimento da parte aérea, enquanto as células das raízes continuam alongando, resultando em incremento na relação raiz/parte aérea. O crescimento da raiz sob condições de baixo potencial de água no solo é o produto dos elevados níveis de ABA endógeno (Sharp \& LeNoble, 2002).

A concentração de $\mathrm{NaCl}$ teve efeito significativo no peso fresco da parte aérea (Tabela 5). Os resultados não apresentaram tendência clara quanto aos efeitos nocivos da salinidade no desenvolvimento da plântula, no entanto observou-se que os valores encontrados seguiram o mesmo comportamento da variável comprimento de parte aérea.
Esperava-se que o aumento das concentrações de sal provocasse a diminuição do peso da parte aérea, conforme a literatura tem descrito em diversos trabalhos.

De acordo com Takemura et al. (2000), tem-se observado que o estresse salino prejudica o desenvolvimento de plantas, por reduzir a expansão da superfície foliar e diminuir consideravelmente a biomassa fresca e seca de folhas e raízes (Chartzoulakis \& Klapaki, 2000). O aumento da salinidade é acompanhado de reduções significativas em peso da parte aérea, altura da planta e número de folhas por planta (Mohammad et al., 1998).

Os efeitos da salinização sobre o crescimento e a distribuição de reservas nas plantas tem sido bem compreendidos. Ainda que a mudança na concentração de sais do meio ocasione declínio no crescimento, a contribuição

Tabela 3 - Comprimento da parte aérea de sementes nuas e revestidas de azevém-anual (Lolium multiflorum L.) em diversas concentrações de $\mathrm{NaCl}(\mathrm{Mm})$

\begin{tabular}{cccc}
\hline Concentração $\mathrm{NaCl}(\mathrm{mM})$ & \multicolumn{2}{c}{ Comprimento da parte aérea $(\mathrm{cm})$} & \multirow{2}{*}{ Médias } \\
\cline { 2 - 3 } & Sementes nuas & Sementes revestidas & $7,08 \mathrm{ab}$ \\
0 & 6,48 & 7,68 & $6,76 \mathrm{ab}$ \\
64 & 5,81 & 7,71 & $7,71 \mathrm{a}$ \\
97 & 8,06 & 7,35 & $6,87 \mathrm{ab}$ \\
129 & 5,98 & 7,76 & $5,83 \mathrm{~b}$ \\
145 & 6,91 & 4,76 & $6,74 \mathrm{ab}$ \\
Médias & 8,00 & 5,47 & $6,79 \mathrm{~A}$ \\
\hline
\end{tabular}

Médias seguidas de mesma letra minúscula nas colunas e maiúsculas nas linhas não diferem $(\mathrm{P}>0,05)$ pelo teste Duncan.

Tabela 4 - Comprimento da raiz de sementes nuas e revestidas de azevém anual (Lolium multiflorum L.) em diversas concentrações de $\mathrm{NaCl}(\mathrm{Mm})$

\begin{tabular}{|c|c|c|c|}
\hline \multirow[t]{2}{*}{ Concentração $\mathrm{NaCl}$ (mM) } & \multicolumn{2}{|c|}{ Comprimento da raiz $(\mathrm{cm})$} & \multirow[t]{2}{*}{ Médias } \\
\hline & Sementes nuas & Sementes revestidas & \\
\hline 0 & 2,25 & 3,23 & $2,74 \mathrm{bc}$ \\
\hline 48 & 1,28 & 3,44 & $2,36 c$ \\
\hline 64 & 3,05 & 3,66 & 3,35ab \\
\hline 97 & 2,81 & 4,06 & $3,44 \mathrm{ab}$ \\
\hline 129 & 2,89 & 1,36 & $2,13 c$ \\
\hline 145 & 3,48 & 3,89 & $3,69 a$ \\
\hline Médias & $2,63 \mathrm{~A}$ & $3,27 \mathrm{~A}$ & \\
\hline
\end{tabular}

Médias seguidas de mesma letra minúscula nas colunas e maiúsculas nas linhas não diferem $(\mathrm{P}>0,05)$ pelo teste Duncan.

Tabela 5 - Peso fresco da parte aérea de sementes nuas e revestidas de azevém-anual (Lolium multiflorum L.) em diversas concentrações de $\mathrm{NaCl}(\mathrm{Mm})$

\begin{tabular}{|c|c|c|c|}
\hline \multirow[t]{2}{*}{ Concentração $\mathrm{NaCl}$ (mM) } & \multicolumn{2}{|c|}{ Peso fresco da parte aérea (g) } & \multirow[t]{2}{*}{ Médias } \\
\hline & Sementes nuas & Sementes revestidas & \\
\hline 0 & 0,0064 & 0,0070 & $0,0067 b$ \\
\hline 48 & 0,0053 & 0,0083 & $0,0068 \mathrm{ab}$ \\
\hline 64 & 0,0091 & 0,0078 & $0,0084 a$ \\
\hline 97 & 0,0066 & 0,0085 & $0,0076 a b$ \\
\hline 129 & 0,0068 & 0,0057 & $0,0062 b$ \\
\hline 145 & 0,0070 & 0,0057 & $0,0065 b$ \\
\hline Médias & $0,0069 \mathrm{~A}$ & $0,0072 \mathrm{~A}$ & \\
\hline
\end{tabular}

Médias seguidas de mesma letra minúscula nas colunas e maiúsculas nas linhas não diferem $(\mathrm{P}>0,05)$ pelo teste Duncan. 
de processos subsequentes, como divisão, expansão e aceleração da morte celular, ainda não foi bem elucidada (Hasegawa et al., 2000).

\section{Conclusões}

A emergência de sementes nuas e revestidas de azevémanual decresce com o aumento da salinidade do meio, afetando negativamente o desenvolvimento de plântulas normais. O aumento dos níveis de cloreto de sódio faz as sementes entrar em dormência. O revestimento usado nas sementes não é capaz de protegê-las da ação prejudicial da salinidade nas maiores concentrações de cloreto de sódio.

\section{Referências}

ASCH, F.; DINGKUHN, M.; DÖRFFLING, K. et al. Leaf K/Na ratio predicts salinity induced yield loss in irrigated rice. Euphytica, v.113, n.1, p.109-118, 2000.

BRESOLIN, A.P.S. Avaliação de populações de azevém quanto à tolerância ao alumínio tóxico e estimativa de tamanho de amostra para estudos de diversidade genética com marcadores AFLP. 2007. 76f. Dissertação (Mestrado em Agronomia) - Faculdade de Agronomia Eliseu Maciel, Universidade Federal de Pelotas, Pelotas.

CAVALCANTE, A.M.B.; PEREZ, S.G.A. Efeito dos estresses hídrico e salino sobre a germinação de sementes de Leucaena leucocephala (Lam.) de Wit. Pesquisa Agropecuária Brasileira, v.30, n.2, p.281-289, 1995.

CHARTZOULAKIS, K.; KLAPAKI, G. Response of two green house pepper hybrids to $\mathrm{NaCl}$ salinity during different growth stages. Scientia Horticulturaer, v.86, n.1, p.247-260, 2000.

DAMIANI, C.R.; MORAES, D.M.; LOPES, N.F. et al. Alterações bioquímicas e fisiológicas em sementes de trigo (Triticum aestivum L.) induzidas por reguladores de crescimento vegetal. Revista Brasileira de Agrociência, v.9, n.4, p.347-352, 2003.

DANTAS, J.P.; FERREIRA, M.M.M.; MARINHO, F.J.L. et al. Efeito do estresse salino sobre a germinação e produção de sementes de caupi. Agropecuária Técnica, v.24, n.2, p.119-130, 2003.

DELOUCHE, J.C.; STILL, T.W.; RASPET, M. et al. O teste de tetrazólio para viabilidade da sementes. Brasília: AGIPLAN, 1976. 103p

EICHELBERGER, L.; MAIA, M.S.; CAMACHO, J.C.B. Períodos de pré-esfriamento na superação da dormência de sementes de azevém anual (Lolium multiflorum Lam.). Revista Brasileira de Sementes, v.23, n.1, p.212-218, 2001.

FLORIANO, E.P. Germinação e dormência de sementes florestais. Santa Rosa: ANORGS, 2004. 19p.

FRETZ, T.A.; READ, P.E.; PEELE, M.C. Plant propagation laboratory manual. Mineapolis: Burgess Publishing, 1979. 317p.

HASEGAWA, P.M.; BRESSAN, R.A.; ZHU, J.K. et al. Plant cellular and molecular responses to high salinity. Annual Review of Plant Physiology and Plant Molecular Biology, v.51, n.1, p.463-499, 2000.

KRAMER, P.J.; BOYER, J.S. Water relations of plants and soils. San Diego: Academic, 1995. 495p.

LARCHER, W. Ecofisiologia vegetal. São Carlos: Prado, 2000. $531 \mathrm{p}$.
LOPES, J.C.; DIAS, M.A. Efeito do estresse salino no vigor e na germinação de sementes e desenvolvimento inicial de plântulas de cenoura. Horticultura Brasileira, v.22, n.2, 2004.

LOPES, J.C.; MACÊDO, C.M.P. Germinação de sementes de couve chinesa sob influência do teor de água, substrato e estresse salino. Revista Brasileira de Sementes, v. 30, p.79-85, 2008.

MACHADO, M.O.; TERRES, A.L. Tolerância de genótipos à salinidade do solo - safra 1994/1995. In: REUNIÃO DA CULTURA DO ARROZ IRRIGADO, 21., 1995, Porto Alegre. Anais... Porto Alegre: Instituto Rio Grandense do Arroz, 1995. p. 48-50

MOHAMMAD, M.; SHIBLI, R.; AJOUNI, M. et al. Tomato root and shoot responses to salt stress under different levels of phosphorus nutrition. Journal of Plant Nutrition, v.21, n.1, p.1667-1680, 1998.

PEREIRA, A.V.; MITTELMANN, A.; LEDO, F.J.S. et al. Comportamento agronômico de azevém anual (Lolium multiflorum L.) para cultivo invernal na região sudeste. Ciência e Agrotecnologia, v.32, n.2, p.567-572, 2008.

QUADROS, F.L.F.; BANDINELLI, D.G. Efeitos da adubação nitrogenada e de sistemas de manejo sobre a morfogênese de Lolium multiflorum Lam. e Paspalum urvillei Steud. em ambiente de várzea. Revista Brasileira de Zootecnia, v.34, n.1, p.44-53, 2005.

QUEIROGA, R.C.; ANDRADE NETO, R.C.; NUNES, G.H.S. et al Germinação e crescimento inicial de híbridos de meloeiro em função da salinidade. Horticultura Brasileira, v.24, n.3, p.315-319, 2006.

SHARP, R.E.; LeNOBLE, M.E. ABA, ethylene and the control of shoot and root growth under water stress. Journal of Experimental Botany, v.53, n.1, p.33-37, 2002.

SAMPAIO, G.T.; SAMPAIO, N.V. Recobrimento de sementes Informativo ABRATES, v.4, n.3, p.20-52, 1994.

SANTOS, H.P.; FONTANELI, R.S.; BAIER, A.C. et al. Principais forrageiras para integração lavoura-pecuária, sob plantio direto, nas regiões planalto e Missões do Rio Grande do Sul. Passo Fundo: Embrapa, 2002. 142p.

SILVA, R.N.; LOPES, N.F.; MORAES, D.M. Physiological quality of barley seeds submitted to saline stress. Revista Brasileira de Sementes, v.29, n.1, p.40-44, 2007.

TAKEMURA, T.; HANAGATA, N.; SUGIHARA, K. et al. Physiological and biochemical responses to salt stress in the mangrove, Bruguiera gymnorrhiza. Aquatic Botany, v.68, n.1, p.15-28, 2000.

TERRA-LOPES, M.L.; CARVALHO, P.C.F.; ANGHINONI, I. et al. Sistema de integração lavoura-pecuária: efeito do manejo da altura em pastagem de aveia preta e azevém anual sobre o rendimento da cultura da soja. Ciência Rural, v.39, n.5, p.1499-1506, 2009.

TOBE, K.; LI, X.; OMASA, K. Seed germination and radicle growth of a halophyte Kalidium capsicum (Chenopodiaceae). Annals of Botany, v.85, n.1, p.391-396, 2000.

TORRES, S.B. Germinação e desenvolvimento de plântulas de melancia em função da salinidade. Revista Brasileira de Sementes, v.29, n.3, p.77-82, 2007.

VERSLUES, P.E.; AGARWAL, M.; KATIYAR-AGARWAL, S. et al. Methods and concepts in quantifying resistance to drought, salt and freezing, abiotic stresses that affect plant water status. The Plant Journal, v.45, n.1, p.523-539, 2006.

WANG, Y.; NIL, N. Changes in chlorophyll, ribulose biphosphate carboxylase-oxygenase, glycine betaine content, photosynthesis and transpiration in Amaranthus tricolor leaves during salt stress. The Journal of Horticultural Science and Biotechnology, v.75, n.1, p.623-627, 2000. 